\title{
The Relationship between Primary School Teacher and Student Attitudes towards Science and Technology
}

\author{
Eddie Denessen, ${ }^{1}$ Nienke Vos, ${ }^{2}$ Fred Hasselman, ${ }^{1}$ and Monika Louws ${ }^{3}$ \\ ${ }^{1}$ Behavioural Science Institute, School of Pedagogical and Educational Science, Radboud University, 6525 HR Nijmegen, Netherlands \\ ${ }^{2}$ HAN University of Applied Sciences, 6503 GL Nijmegen, Netherlands \\ ${ }^{3}$ ICLON Leiden University Graduate School of Teaching, 2333 AL Leiden, Netherlands
}

Correspondence should be addressed to Eddie Denessen; e.denessen@pwo.ru.nl

Received 26 September 2014; Accepted 11 February 2015

Academic Editor: Gwo-Jen Hwang

Copyright (C) 2015 Eddie Denessen et al. This is an open access article distributed under the Creative Commons Attribution License, which permits unrestricted use, distribution, and reproduction in any medium, provided the original work is properly cited.

\begin{abstract}
This study focuses on the effects of teachers' attitudes towards teaching about science and technology on student attitudes towards science and technology. A one-year longitudinal study involving 91 teachers and 1822 students from the higher years of Dutch primary schools showed that students develop less positive attitudes towards science and technology during their primary school years and that girls showed less positive attitudes than boys. Female teachers showed less positive attitudes towards teaching about science and technology than male teachers. Girls appeared to be susceptible of their teacher's attitudes and especially developed less positive attitudes when their female teacher showed less enthusiasm for teaching science and technology. Implications for teacher education and teacher recruitment are discussed.
\end{abstract}

\section{Introduction}

In many countries, there is some concern that the enrolment in technical and scientific professions is declining and that it is necessary to recruit more students for a career in science and technology $[1,2]$. The cause for students not choosing science and technology related studies is usually not concerned with students' abilities but with their perceived attractiveness of science and technology related subjects. Therefore, many programs have been developed to get students more enthusiastic for studying science and technology related subjects in order to maximise the chances of them opting for a future career in these fields. These programs mainly aim at strengthening primary school teachers' attitudes, competences, and self-efficacy regarding science teaching (see, e.g., [3-5]). These programs thus assume that teacher competences and attitudes affect student attitudes. In the present study we explored the relationship between primary school teachers' attitudes towards science and technology and the attitudes of their students. With this study we aimed to gain insight into the presumed effects that teacher attitudes have on the development of student attitudes. For this purpose we set up a one-year longitudinal study in which teacher attitudes were related to their students' attitudes at the beginning and at the end of the school year.

\section{Student Attitudes towards Science and Technology}

Students generally do not seem to like to study science and technology very much. Research on student attitudes towards science and technology consistently points to an increasingly negative attitude towards science in students when they get older. It is suggested that students develop their attitudes towards science and technology at an early age. Research indicates that student attitudes towards science and technology are formed between the ages of 10 and 14. At the age of 14, it seems that student attitudes have been formed. These largely affect their future career choices [6].

A major debate in student career prospects and choices, especially with respect to science and technology, is focused on gender differences. Women are underrepresented in science and technology related professions $[1,7]$. This job inequality is not caused by girls' underachievement, but it is 
the result of choices girls make during their school careers [1]. In fact, girls achieve at least on a par with boys $[8,9]$. In contrast to their achievement in science and technology, girls tend to have more negative attitudes towards science and technology than boys $[7,9,10]$.

\section{Teacher Attitudes towards Teaching Science and Technology}

As is the case in many other countries and unlike secondary school teachers, Dutch primary school teachers do not need to specialize in specific subject areas. Primary school teachers provide teaching in many subject areas and their enjoyment in teaching varies across subjects. Primary school teachers have been found to rate science among the least enjoyable subjects to teach [11]. It is therefore likely that teachers vary in the degree to which they show enthusiasm while teaching science and technology [12-14].

Unfavourable attitudes towards teaching science and technology are presumably related to relatively low feelings of competence and low levels of self-efficacy in science and technology teaching [15]. Female teachers generally show lower levels of feelings of competence and self-efficacy about teaching science and technology than male teachers $[3,16]$. It can be expected that their enthusiasm for teaching science and technology is affected by their perceived competence. In this study we explored teachers' enjoyment in teaching about science and technology that is likely to affect student attitudes $[5,7]$.

\section{Teacher Attitudes and the Formation of Student Attitudes towards Science and Technology}

Schools play a major role in the development of students attitudes [17]. According to social cognitive learning theories, children learn by observing standards and behaviors of their teachers. Students shape their attitudes towards a subject by listening to teachers' comments and by observing their teachers' enjoyment when teaching about a topic [18]. Teachers thus may influence students' experiences via their abilities to (accidentally or intentionally) instil values and beliefs in their teaching and students may adopt these values and beliefs as their own attitudes [18]. As a result, teachers' high task values may have positive effects on students' enjoyment of learning [19]. On the other hand, teacher's negative associations, captured in their teaching, could also be observed by students. Therefore, it is suggested that teacher enjoyment in teaching is considered one of the most important characteristics of effective teaching $[18,20]$. Students' enjoyment in learning about science and technology can very well be positively stimulated by teachers' enthusiasm about the subjects they teach.

Teacher attitudes, such as teacher enjoyment, might thus play an important role in student attitude development. Although there is relatively little known about the teacher's role in student attitude development, there is some empirical evidence confirming this relationship. For example, Frenzel et al. [18] found that teacher enjoyment was positively related to student enjoyment. The more teachers enjoyed the teaching, the more enthusiastic they taught and the more students enjoyed the lesson. Similar effects of teachers' attitude towards their teaching subject were shown already in the 1960s by Mastin [21], who found that teacher attitudes towards a specific subject influenced student attitudes towards this subject. Moreover, teachers who lacked ability, confidence, and enthusiasm were more likely to have students with poor attitudes [22]. A positive teacher attitude thus seems to be crucial in the development of positive student attitudes. As female teachers tend to have less positive attitudes towards science and technology than their male counterparts, teachers' gender might also play an important role in student attitude development.

4.1. The Present Study. With the present study we aimed to give some insights into the development of student attitudes towards science and technology and relations with their teachers' attitudes. It was investigated to what extent primary school teachers' attitudes towards science and technology were related to student attitude development during one school year. In addition, considerations were made as to whether this relation differed by teacher and student gender. The following research questions guided the study.

(1) How do boys' and girls' attitudes towards science and technology develop during one school year?

(2) To what extent do attitudes of male and female teachers relate to their students' attitude development?

\section{Methods}

5.1. Participants. To investigate the relationship between teacher and student attitudes towards science and technology, we approached Dutch primary schools that were part of a national network of schools (VTB) that received allowance for improving their science and technology curriculum (VTB (verbreding techniek basisonderwijs, "broadening science in primary schools") is part of the "Platform Bèta Techniek," that has been commissioned by the government, education, and business sectors to ensure sufficient availability of people who have a background in scientific or technical education (http://www.platformbetatechniek.nl)). Since schools take part in this network voluntarily, we cannot claim this sample to be a good representation of the population of Dutch primary schools. After an open invitation to participate in our study was sent out via the network's newsletter, 31 schools signed up for this study.

The total sample of this study consisted of 91 teachers (56 females and 35 males) and their 1822 pupils (896 boys and 926 girls) from year 5 (601 pupils around 8 and 9 years old), year 6 (577 pupils around 9 and 10 years), year 7 (542 pupils around 10 and 11 years), and year 8 (102 pupils around 11 and 12 years). Initially, we planned to focus on students from year 5 to year 7. Since some teachers taught multigrade classes, it was decided to let their year 8 students participate as well. All year 8 students in this sample thus are students from multigrade classes. The teachers' work experience varied between 1 and 
38 years $($ mean $=17.07, \mathrm{sd}=12.08)$. Part of the teachers $(28.6 \%)$ taught multigrade classes of two or three different years.

5.2. Instruments. Questionnaires were used to gain insight in student and teacher attitudes toward science and technology. Student and teacher attitudes were assessed at the beginning of the school year (pretest: October 2009). At the end of the school year (posttest: June 2010), the student attitudes again were assessed.

5.2.1. Student Attitudes. The student attitude questionnaire consisted of five items. We took items from previous studies on student attitudes towards science and technology [7, 9] to measure enjoyment of learning about science and technology. In order to ensure that the students had a clear understanding about the content of the concepts of science and technology, concepts (such as tools, rocket, electricity, energy, machine, telescope, and graphs) and jobs (such as astronaut, biologist, plumber, inventor, researcher, and mathematician) that were related to science and technology were presented.

An example of a questionnaire item is "I enjoy to learn about science and technology." The students had to rate their level of agreement with the statements on a four point Likert scale. The reliability (Cronbach's alpha) of the attitude scale was good (beginning of school year: .74; end of school year: $.80)$. There was a strong correlation between the measures at the beginning and the end of the school year $(r=.53, P<$ $.01)$.

5.2.2. Teacher Attitudes. The teacher questionnaire about their attitudes towards science and technology consisted of 10 items that were selected from previous measures of attitudes, such as the Revised Science Attitude Scale [23], science attitude items from the PISA-study [9], and items from a previously validated Dutch questionnaire [24]. With the questionnaire we aimed at measuring two dimensions of attitudes towards science and technology: teachers' enjoyment for teaching science and technology (e.g., "I enjoy teaching about science and technology") and their perceived level of competence and efficacy related to teaching science and technology (e.g., "for me teaching science and technology is very difficult"). Teachers were given the same illustrations of concepts and jobs that were to be associated with science and technology. Each attitude aspect was indicated with five questionnaire items. Teachers were asked to rate their agreement with the statements on a four-point Likert scale. Oblique rotated factor analysis resulted in two distinct but strongly related aspects of teacher attitudes $(r=.70, P<.01)$. The reliability (Cronbach's alpha) of both scales was good (enjoyment .84, perceived competence .70).

5.3. Data Analysis. First, $t$-tests and analyses of variance were applied to assess differences between attitudes of boys and girls from different years and differences between the beginning and the end of the school year.

Second, multilevel regression analyses were conducted to gain insight into the role of teacher attitudes in student attitude development. Because students are nested within
TABLE 1: Descriptive statistics of beginning and end of school year student attitudes towards science and technology (range 1-4).

\begin{tabular}{llccccc}
\hline & & \multicolumn{4}{c}{ Student enjoyment } \\
& & $n$ & \multicolumn{2}{c}{ Beginning } & \multicolumn{2}{c}{ End } \\
& & & $\mathrm{m}$ & $\mathrm{sd}$ & $\mathrm{m}$ & $\mathrm{sd}$ \\
\hline \multirow{3}{*}{ Year 5 } & Boys & 309 & 3.32 & .59 & 3.28 & .67 \\
& Girls & 292 & 3.24 & .56 & 3.27 & .61 \\
& Total & $\mathbf{6 0 1}$ & $\mathbf{3 . 2 8}$ & $\mathbf{. 5 8}$ & $\mathbf{3 . 2 7}$ & $\mathbf{. 6 4}$ \\
\hline \multirow{4}{*}{ Year 6 } & Boys & 280 & 3.41 & .52 & 3.30 & .55 \\
& Girls & 297 & 3.21 & .56 & 3.10 & .60 \\
& Total & $\mathbf{5 7 7}$ & $\mathbf{3 . 3 1}$ & $\mathbf{. 5 5}$ & $\mathbf{3 . 2 0}$ & $\mathbf{. 5 9}$ \\
\hline \multirow{4}{*}{ Year 7 } & Boys & 261 & 3.32 & .57 & 3.19 & .59 \\
& Girls & 281 & 3.04 & .63 & 2.88 & .64 \\
& Total & $\mathbf{5 4 2}$ & $\mathbf{3 . 1 7}$ & $\mathbf{. 6 2}$ & $\mathbf{3 . 0 3}$ & $\mathbf{. 6 4}$ \\
\hline \multirow{4}{*}{ Year 8 } & Boys & 46 & 2.96 & .52 & 2.82 & .56 \\
& Girls & 56 & 2.51 & .63 & 2.39 & .62 \\
& Total & $\mathbf{1 0 2}$ & $\mathbf{2 . 7 2}$ & $\mathbf{. 6 2}$ & $\mathbf{2 . 5 8}$ & $\mathbf{. 6 3}$ \\
\hline \multirow{2}{*}{ Total } & Boys & 896 & 3.33 & .57 & 3.24 & .62 \\
& Girls & 926 & 3.13 & .61 & 3.04 & .66 \\
& Total & $\mathbf{1 8 2 2}$ & $\mathbf{3 . 2 2}$ & $\mathbf{. 6 0}$ & $\mathbf{3 . 1 4}$ & $\mathbf{. 6 4}$ \\
\hline
\end{tabular}

teachers and some teachers taught multigrade classes, crossclassifications of students within teachers and years were made. Additionally, the variance for boys and girls was modelled separately, since student attitudes did not appear to have a homogeneous variance across student gender. A model was fitted with the student end of the year attitude scores as the dependent variable. Students beginning of the year scores were entered as a covariate resulting in a residualised gain score analysis for each fixed teacher effect added to the model. The teacher covariates used in all four models were teacher attitude and teacher gender and the interaction term of teacher attitude and teacher gender. Because of the high correlation between both teacher attitudes, which would lead to problems related to colinearity, we decided to only use the teacher enjoyment attitude in the analyses.

Cross-level interactions were added to the model, but none of these predictors reached statistical significance and none of them resulted in a better fit. Also, aggregated attitude scores of boys and girls in classes did not significantly contribute to the model. We therefore did not include them in further analyses. The models were estimated using MLwiN 2.18 .

\section{Results}

6.1. Student Attitudes. Student descriptive statistics are presented in Table 1. When we look at the attitude development of the students, we can conclude that both boys and girls enjoyed science and technology more in the beginning of the school year, compared to the end of the school year, $F_{(1,1820)}=$ 36.67, $P<.001$.

Comparing the attitudes of boys and girls, it turned out that boys evaluated science and technology more favourable than girls did. Compared to girls, boys reported significantly 
TABLE 2: Descriptive statistics of teacher attitudes towards science and technology (range 1-4).

\begin{tabular}{lccccc}
\hline & $n$ & \multicolumn{2}{c}{ Enjoyment } & \multicolumn{2}{c}{ Perceived competence } \\
& & $\mathrm{m}$ & $\mathrm{sd}$ & $\mathrm{m}$ & $\mathrm{sd}$ \\
\hline Male & 35 & 3.22 & .44 & 2.98 & .40 \\
Female & 56 & 2.86 & .59 & 2.73 & .42 \\
\hline Total & 91 & 3.00 & .56 & 2.82 & .43 \\
\hline
\end{tabular}

higher levels of enjoyment (pretest: $t_{(1820)}=7.43, P<.001$, $d=0.34$, posttest: $\left.t_{(1817.96)}=6.49, P<.001, d=0.30\right)$. Also students seemed to report more negative attitudes in successive years (pretest: $F_{(3,1818)}=33.08, P<.001$, posttest: $\left.F_{(3,1818)}=44.11, P<.001\right)$.

6.2. Teacher Attitudes. In Table 2, the descriptive statistics of teacher attitudes are presented. As can be seen from Table 2, there were some gender differences in teachers' attitudes towards science and technology. Male teachers reported significantly higher levels of enjoyment in teaching about science and technology than their female counterparts $\left(t_{(89)}=3.15, P=.002, d=0.59\right)$. Male and female teachers also differed in their perceived competence $t_{(89)}=2.91$, $P=.005, d=0.56$ ); male teachers reported higher levels of competence than women. As has been mentioned, there was a strong relation between both attitudes, implying that teachers' enjoyment in teaching about science and technology was linked to their perceived competences.

6.3. Multilevel Models. In each multilevel model the teachers' role in student attitude development was examined. For each dependent variable (end of school year student enjoyment, perceived societal relevance, perceived competence, and future aspirations) the same modelling strategy was used. The modelling strategy was as follows: for each dependent variable a single level empty model (model 0) was estimated, which consisted of the dependent variable and the boys and girls indicator variables. This model served as baseline to evaluate whether multilevel modelling is warranted for each dependent variable. Hereafter the random intercept variance on the teacher level for boys and for girls was estimated in model 1 (random intercepts model). In model 2 grade was entered as a third source of random variation, indicating a cross classification of students between teachers and school years. In model 3 student pretest score was entered as a covariate (residualised gain analysis). In model 4 we allowed the relation between the student attitudes at the beginning of the school year and those at the end of the school year to vary randomly between teachers (random slopes model). In model 5 the teacher attitude was entered. Hereafter teacher gender was entered as a dummy variable with male teacher as a reference in model 6 . In model 6 the interaction of teacher gender and teacher attitude was also added. Each model could be compared to the previous one, in order to determine the added value of subsequent predictors.
6.4. Relations between Teacher and Student Attitudes. Multilevel models for student enjoyment are shown in Table 3. As can be noticed in the table, differences between students could to some extent be attributed to teachers; allowing variance at teacher level resulted in a significant deviance drop (model 0 versus model 1). This variance at teacher level is different for boys and girls, as we can see from the intraclass correlation (ICC). The ICC of model 1 was .045 for boys and .156 for girls, which shows that $4.5 \%$ of the variance in boys' enjoyment in the end of the school year was at teacher level and $95.5 \%$ at student level, while for the girls $15.6 \%$ of variance can be attributed to differences between teachers and $84.4 \%$ to differences between students. The random variances at the teacher level were significant, for both boys and girls. These significant teacher variances indicate that the teachers play a role in student enjoyment. In addition to the teacher level, we investigated whether differences between students could be explained by the school year. The addition of school year to the model resulted in a better fit (model 2 versus model 1). It can also be seen that the intercept variance for boys at the teacher level was no longer significant. For girls, however, there still remained variance to be explained at the teacher level.

When controlling for student enjoyment in the beginning of the school year (model 3), the variance between teachers drops with $18.5 \%$ for girls (Proportional reduction for girls: $(0.027-0.022) / 0.027=0.185)$. As noticed before, there was no significant variance for boys at teacher level left after adding school year to the model. Student enjoyment in the beginning of the school year is a predictor for student enjoyment at the end of the school year, where high reported enjoyment in learning about science and technology at the beginning of the school year meant high enjoyment at the end of the school year. However, there is still variance to be explained. Allowing random slopes of student enjoyment in the beginning of the year also resulted in a better fit (Model 4). The significant random slopes indicate that a unit change in students' enjoyment in the beginning of the school year resulted in a different change in enjoyment for students of different teachers. The significant intercept variance for girls on teacher level suggests there is still variance to be explained on teacher level for girls.

In model 5 teacher enjoyment was added to the model. The significant deviance drop indicates that teacher enjoyment contributed to student development of enjoyment in science and technology during the school year. The more enjoyment a teacher had, the more students enjoyed science and technology in the end of the school year. Teacher gender was added in Model 6. As can be seen in Table 3, teacher gender contributed significantly to student enjoyment in the end of the school year. The negative coefficient indicates that female teachers contributed negatively to student enjoyment in the end of the school year. This was particularly the case for girls, given the amount of proportional reduction of variance on teacher level and the nonsignificant teacher variance for boys. In the final model the interaction of teacher gender and teacher enjoyment was added. The addition of this parameter resulted in the best fitting multilevel model to predict student enjoyment at the end of the school year. 


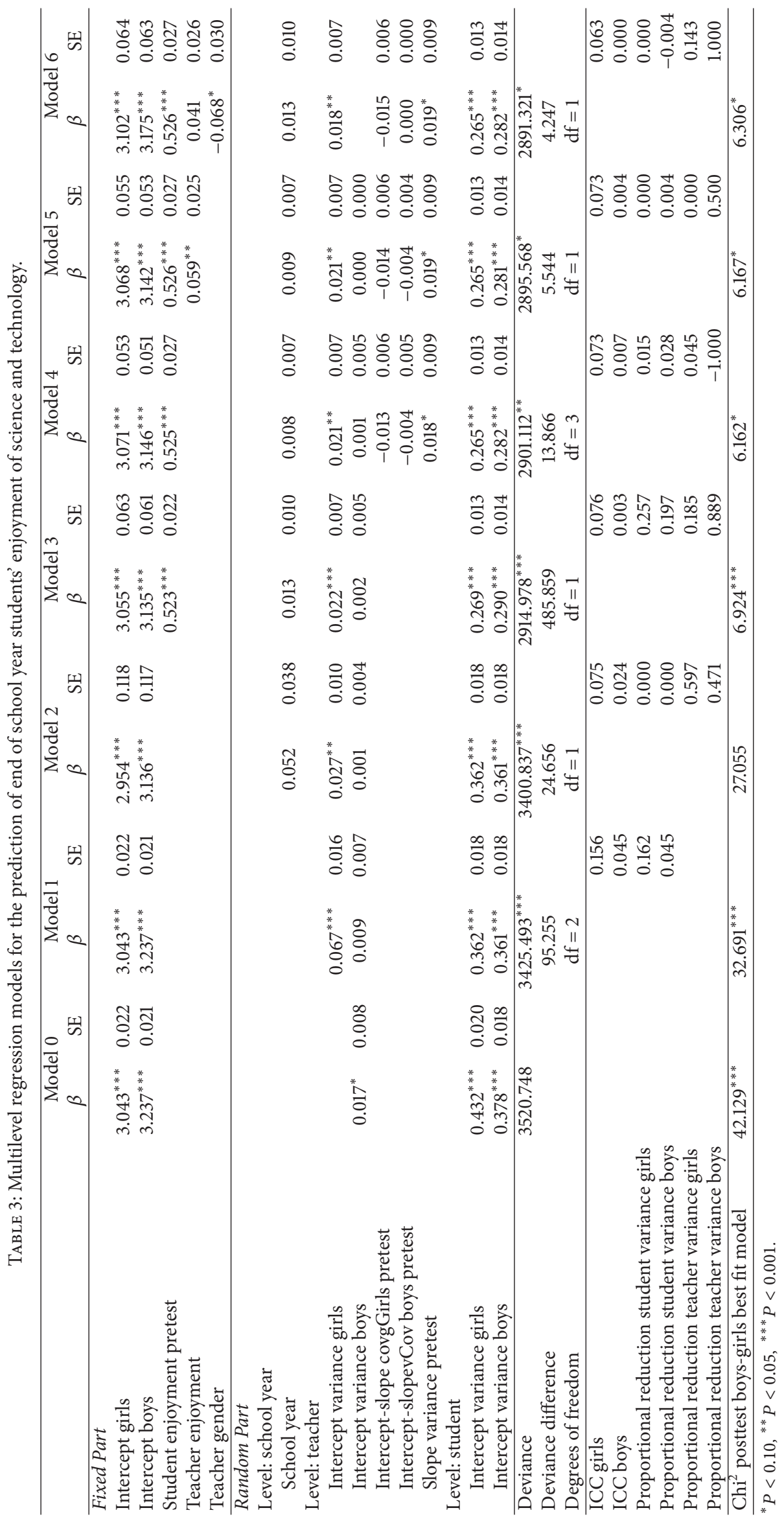


The positive coefficient of the interaction term indicates that the effect of female teachers' reported enjoyment in teaching science and technology on student enjoyment at the end of the school year is stronger than the effect of male teachers' enjoyment. This also is particularly true for girls, since there was no significant variance on teacher level for boys left.

\section{Discussion}

In this study, the development of students' attitudes towards science and technology in the higher years of primary school was studied in relation to teachers' enjoyment in teaching about science and technology. The results of this one year longitudinal study revealed that girls showed lower levels of enjoyment in learning about science and technology than boys and that student attitudes decrease when students grow older. We also found teacher attitudes to affect student attitudes. Students show a stronger decrease in their attitudes when teachers are less enthusiastic about teaching science and technology. In particular girls' attitudes seemed to be affected by less positive attitudes of female teachers. With respect to teacher attitudes female teachers appeared to experience less enjoyment in teaching science and technology and to feel less competent in this respect.

The results of this multilevel study are in line with previous studies that report differences in attitudes between boys and girls [2]. In general, girls were less positive about science and technology than boys. Girls also seemed more susceptible to teacher attitudes than boys. Low teacher enthusiasm fosters negative attitudes towards science and technology in girls. This was especially the case for female teachers. This finding can be explained by the fact that female teachers act as a role model for girls. In their science and technology teaching practice, female teachers may send verbal and nonverbal signals that reveal that they do not like to teach about these subjects. In a previous study, Beilock et al. [15] found that girls' math achievement was affected by female teachers' math anxiety. For future research it might be interesting to study teachers' verbal and nonverbal behaviour during science education.

Beilock et al. found that the relation between female teachers' math anxiety and girls' math performance was mediated by girls' gender stereotyped beliefs about math. In their teaching, female teachers may give clues that they find science and technology more suitable for male teachers to teach and more suitable for boys to learn about. The existence of gender stereotyping related to science and technology learning has been established in numerous studies (e.g., [1, 25]). For future research the impact of teachers' stereotyped attitudes on student attitudes may be studied with a similar multilevel approach to get a better understanding of the way teachers act as socializing agents of student attitudes.

This study has some limitations that are especially related to the selection of teachers for this study. The teachers who were involved in this study were part of a national network for science teaching in primary schools (VTB). This means that at these schools, policies and practices were developed to improve science education. Possible biases that may have resulted from this selective sample may be that the teachers in this study were more positive about science and felt more competent than the average teacher in Dutch primary schools. On the other hand, these teachers may have faced difficulties with the implementation of science education innovations that could have contributed to feelings of incompetence or negative attitudes.

The results of our study have some practical implications for teacher education and teacher recruitment. It seems fruitful to invest in the empowerment of female teachers in their teaching about science and technology related subjects. Reducing female teachers' negative attitudes might be a specific focus of teacher educators. In this respect. Tytler and Osborne [2] point to good subject knowledge as a necessary condition because it provides a base level of confidence.

Besides investing in teacher education, schools may decide to recruit subject specialists to teach science and technology at primary schools [26]. Since teacher enthusiasm plays an important role in the formation of positive student attitudes, students may benefit from enthusiastic teachers who feel confident and competent in the subjects they teach. Attracting subject specialists may counter the negative attitude development of students in primary schools.

\section{Conflict of Interests}

The authors declare that there is no conflict of interests regarding the publication of this paper.

\section{References}

[1] C. Hill, C. Corbett, and A. St. Rose, Why So Few? Women in Science, Technology, Engeneering and Mathematics, AAUW, Washington, DC, USA, 2010.

[2] R. Tytler and J. Osborne, "Student attitudes and aspirations towards science," in Second International Handbook of Science Education, B. J. Fraser, Ed., pp. 597-625, Springer, 2012.

[3] R. E. Bleicher, "Revisiting the STEBI-B: measuring self-efficacy in preservice elementary teachers," School Science and Mathematics, vol. 104, no. 8, pp. 383-391, 2004.

[4] W. Harlen and P. Léna, "Introduction to the theme," in Professional Development for Primary Teachers in Science and Technology, M. de Vries, H. van Keulen, S. Peters, and J. W. van der Molen, Eds., pp. 1-16, Sense Publishers, Rotterdam, The Netherlands, 2008.

[5] T. Jarvis and A. Pell, "Primary teacher's changing attitudes and cognition during a two-year science in-service programme and their effect on pupils," International Journal of Science Education, vol. 26, no. 14, pp. 1787-1811, 2004.

[6] J. Osborne, S. Simon, and R. Tytler, "Attitudes towards science: an update," in Proceedings of the Annual Meeting of the American Educational Research Association, San Diego, Calif, USA, April 2009.

[7] J. Osborne, S. Simon, and S. Collins, "Attitudes towards science: a review of the literature and its implications," International Journal of Science Education, vol. 25, no. 9, pp. 1049-1079, 2003.

[8] J. Elwood and C. Comber, "Gender differences in A level examinations: new complexities or old stereotypes?" The British Journal of Curriculum and Assessment, vol. 6, no. 2, pp. 24-29, 1996. 
[9] OECD, PISA 2006: Science Competencies for Tomorrows World, OECD Programme for International Student Assessment, 2006.

[10] P. Kind, K. Jones, and P. Barmby, "Developing attitudes towards science measures," International Journal of Science Education, vol. 29, no. 7, pp. 871-893, 2007.

[11] J. L. M. Wilkins, "Elementary school teachers' attitudes toward different subjects," The Teacher Educator, vol. 45, no. 1, pp. 23$36,2010$.

[12] D. Huinker and S. K. Madison, "Preparing efficacious elementary teachers in science and mathematics: the influence of methods courses," Journal of Science Teacher Education, vol. 8, no. 2, pp. 107-126, 1997.

[13] D. Palmer, "Situational interest and the attitudes towards science of primary teacher education students," International Journal of Science Education, vol. 26, no. 7, pp. 895-908, 2004.

[14] R. Trumper, "The need for change in elementary-school teacher training: the force concept as an example," Asia-Pacific Journal of Teacher Education, vol. 26, no. 1, pp. 7-25, 1998.

[15] S. L. Beilock, E. A. Gunderson, G. Ramirez, and S. C. Levine, "Female teachers' math anxiety affects girls' math achievement," Proceedings of the National Academy of Sciences of the United States of America, vol. 107, no. 5, pp. 1860-1863, 2010.

[16] L. G. Enochs, "Further development of an elementary science teaching efficacy belief instrument: a preservice elementary scale," School Science and Mathematics, vol. 90, no. 6, pp. 453453, 1990.

[17] H. A. Davis, "Conceptualizing the role and influence of studentteacher relationships on children's social and cognitive development," Educational Psychologist, vol. 38, no. 4, pp. 207-234, 2003.

[18] A. C. Frenzel, T. Goetz, O. Lüdtke, R. Pekrun, and R. E. Sutton, "Emotional transmission in the classroom: exploring the relationship between teacher and student enjoyment," Journal of Educational Psychology, vol. 101, no. 3, pp. 705-716, 2009.

[19] R. Pekrun, "A social cognitive, control-value theory of achievement emotions," in Motivational Psychology of Human Development, J. Heckhausen, Ed., pp. 143-163, Elsevier, Oxford, UK, 2000.

[20] E. M. Bettencourt, M. H. Gillett, M. D. Gall, and R. E. Hull, "Effects of teacher enthusiasm training on student on-task behavior and achievement," American Educational Research Journal, vol. 20, no. 3, pp. 435-450, 1983.

[21] V. E. Mastin, “Teacher enthusiasm," The Journal of Educational Research, vol. 56, no. 7, pp. 385-386, 1963.

[22] J. Osborne and S. Simon, "Primary science: past and future directions," Studies in Science Education, vol. 27, pp. 99-147, 1996.

[23] B. L. Bitner, "Revised science attitude scale for preservice elementary teachers: re-examined," in Proceedings of the Annual Meeting of The National Association for Research in Science Teaching, Anaheim, Calif, USA, 1994.

[24] J. Walma van der Molen, "What do teachers think of science and technology?" in Research on Science and Technology in Dutch Primary Education, H. van Keulen and J. Walma van der Molen, Eds., pp. 157-163, Platform Bèta Techniek, The Hague, The Netherlands, 2009.

[25] B. A. Nosek, F. L. Smyth, N. Sriram et al., "National differences in gender-science stereotypes predict national sex differences in science and math achievement," Proceedings of the National Academy of Sciences of the United States of America, vol. 106, no. 26, pp. 10593-10597, 2009.
[26] K. Ardzejewska, A. Mcmaugh, and P. Coutts, "Delivering the primary curriculum: the use of subject specialist and generalist teachers in NSW," Issues in Educational Research, vol. 20, no. 3, pp. 203-219, 2010. 

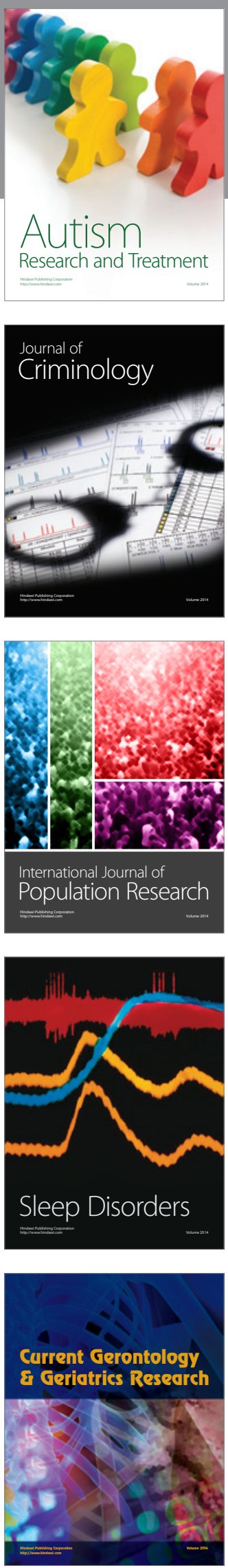
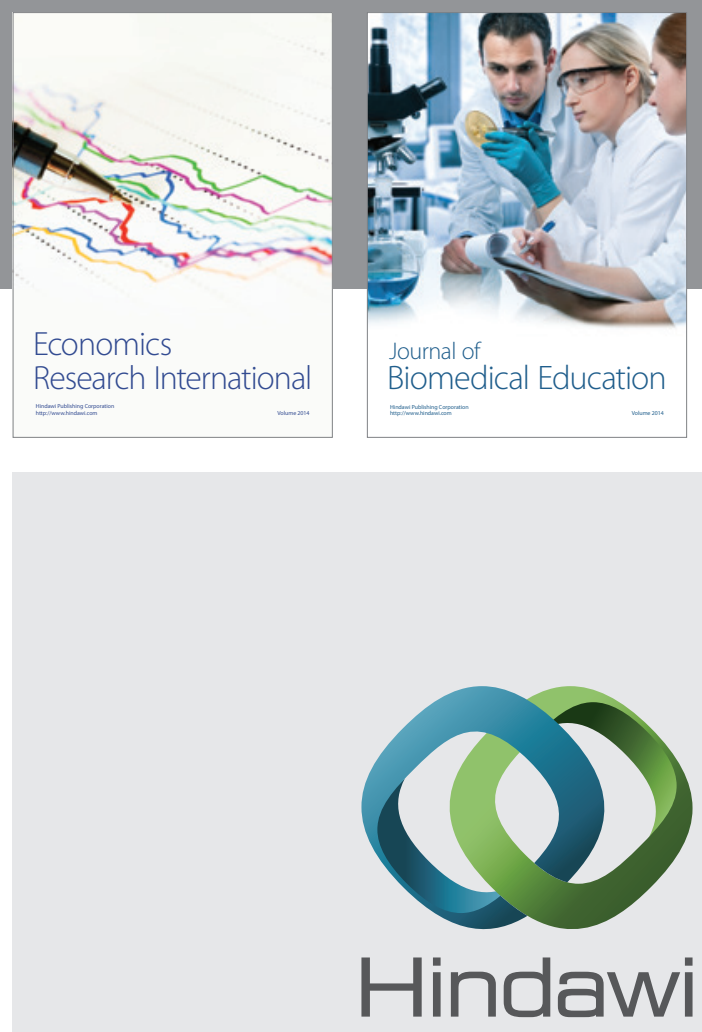

Submit your manuscripts at

http://www.hindawi.com
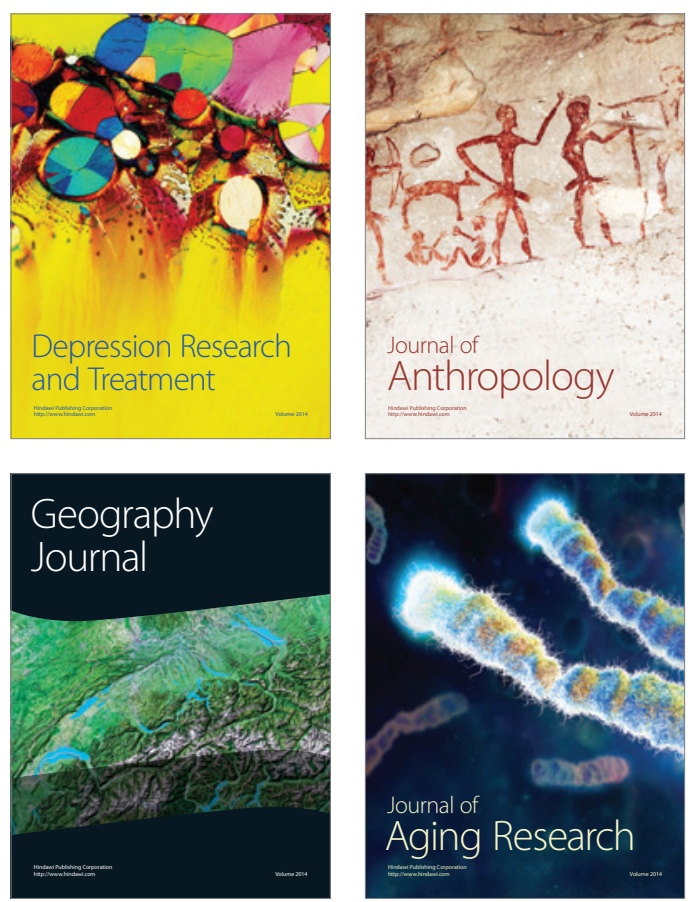
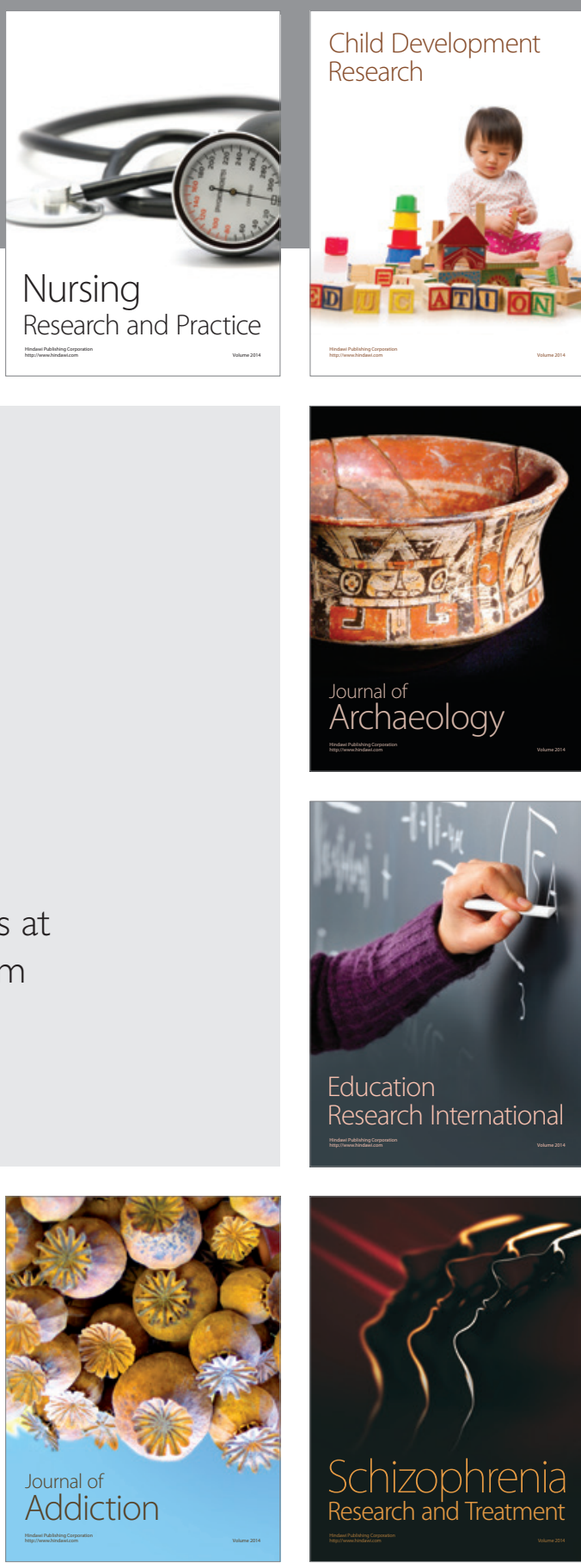

(D)
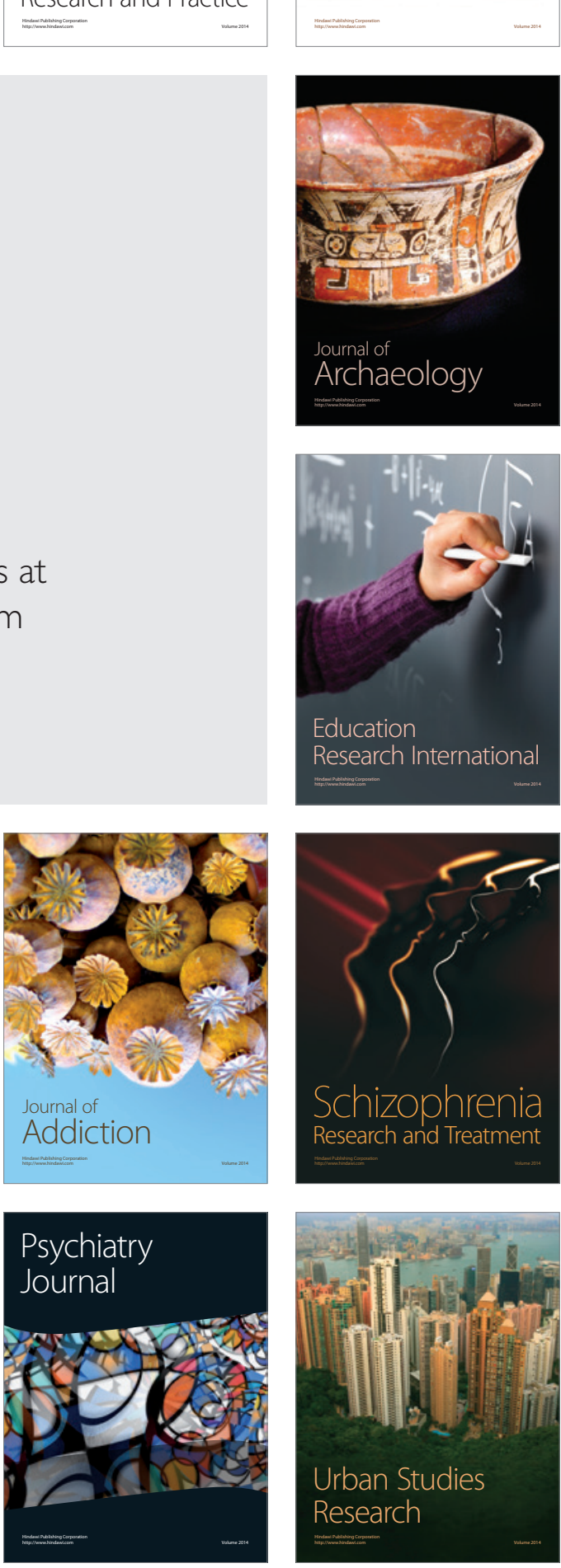